\title{
The third sense of environment
}

\author{
Edward Baggs ${ }^{1}$ and Anthony Chemero ${ }^{2}$ \\ ${ }^{1}$ Bartlett School of Architecture \\ University College London \\ ${ }^{2}$ Center for Cognition, Action, and Perception \\ University of Cincinnati
}

(Draft for Wagman and Blau (eds.) Perception as Information Detection: Reflections on Gibson's Ecological Approach to Visual Perception, Taylor and Francis.)

\section{Introduction}

James Gibson begins his final book by making a distinction between two senses in which the world surrounds the animal. The whole project of The Ecological Approach to Visual Perception depends upon the distinction Gibson makes between the physical world surrounding animals and the environment surrounding them. The physical world contains everything from sub-atomic particles to galaxies, but it does not contain meaning. Perception does contain meaning. If the world that animals perceive is the physical world, it is mysterious why perception is meaningful. The traditional solution to this mystery, which Gibson rejected, is that animals make the meaning somehow. For animals like us, the traditional solution has it that our brains construct the meaning in private, and that is where the meaning lives. In proposing that the world that animals perceive is the environment, not the physical world, Gibson proposes a different solution to this mystery. Perception contains meaning because there is meaning in the environment that animals perceive. Animals do not create meaning; they discover it in the environment. Gibson's solution amounts to a radical rejection of the understanding of the nature of the world and its relationship to experience, perception, and knowledge that had been in place since the founding of modern science. Gibson's solution is the key move that motivates the rest of his book, and indeed the whole of his ecological approach to psychology. The distinction has, however, created new problems. The purpose of this chapter is to argue that 
Gibson should have made a distinction between not just two, but three different senses in which the world surrounds the animal.

The distinction Gibson (1979/2015) makes is between the following:

1.The physical world: Reality is assumed to be structured in various ways, prior to and irrespective of the existence of any animal living in it. This structure is properly the subject matter of physics and geology.

2. The environment: Animals themselves do not perceive the world of physics - of planets and atoms. Animals have evolved to perceive and act at the terrestrial scale, relative to objects and surfaces that are meaningful because they offer possibilities for action. To talk of an environment is to imply the existence of an animal that is surrounded. The two terms are mutually codependent, and it is in this sense that the animal and its environment constitute an animal-environment system.

This distinction is both appropriate and intuitively appealing. But it fails to include a further distinction: that between the evolutionary history of a species and the personal history of a particular individual animal. These are quite different things. We suggest that Gibson's lumping together of these ideas has led to no small number of confusions, and to unnecessary controversy among proponents of ecological psychology.

It is necessary to subdivide what Gibson called the environment into two quite distinct concepts. We propose to replace his two-way distinction with a three-way distinction between, 1) the physical world, 2) the species habitat, and 3) the animal-specific umwelt.

\section{A troublesome observation}

The additional distinction we are proposing here is not novel. Gibson himself was quite aware that his use of 'environment' referred ambiguously to both the surroundings of an individual living animal and the surroundings of an idealized member of a species, and he noted that this ambiguity could potentially cause confusion. Gibson writes (1979/2015, p. 3):

The environment consists of the surroundings of animals. Let us observe that in one sense the surroundings of a single animal are the same as the surroundings of all animals but that in another sense the surroundings of a single animal are different from those of any other animal. These two senses of the term can be troublesome and may cause confusion. The apparent contradiction can be resolved, but let us defer the problem until later. (The solution lies in the fact that animals are mobile.) 
As is clear here, Gibson thought he could resolve the confusion by pointing out that animals move around. Gibson elaborates on this at the end of chapter 3 (Gibson, 1979/2015, p. 38):

In the course of time, each animal moves through the same paths of its habitat as do other animals of its kind. Although it is true that no two individuals can be at the same place at the same time, any individual can stand in all places, and all individuals can stand in the same place at different times. Insofar as the habitat has a persisting substantial layout, therefore, all its inhabitants have an equal opportunity to explore it. In this sense the environment surrounds all observers in the same way that it surrounds a single observer.

What Gibson says here is more or less true. For most of the objects and surfaces around us, we can station our eyeballs relative to those surfaces at a viewing position that was previously occupied by one of our fellows. (There are exceptions to this: only you can see the end of your own nose from the position of your own eyeball, Gibson 1967.)

But this does not really resolve the tension. There are many ways in which the world can look different to two different members of the same species, even if we all keep moving around in the appropriate way. This is not because we are trapped in our own private mental world, as the traditional view has it, but simply because we are different animals with different abilities.

Take a Chinese newspaper. Neither of the authors of this chapter knows how to read Chinese. We might be able to recognize the general shape of the characters and make the judgment, "That looks like Chinese writing," or again we might recognize someone in a photograph printed on the front page. But we cannot read any of the headlines. The script is not meaningful for us in the way that it is for someone who can read Chinese. Similarly, the cockpit of a plane looks different to a trained pilot than it does to a novice or to a child. The pilot can do things with the buttons and levers that non-trained individuals cannot. Or, at an even more basic level, think about climbing a set of stairs. The stairs look different depending on whether you are a toddler or a long-jumper or you are someone who has just had a hip operation or you are wearing high-heeled shoes.

What's missing, in Gibson's eliding of the two senses of environment here, is an acknowledgement that the way the world looks to us is to some extent a result of the way we currently are as individuals. In claiming that we all share the same environment because we can in principle all see the same surfaces from the same set of positions, Gibson is treating perception as if it were an idealized process. He is suggesting that perception can be separated from the perception-action loop that comprises the activity of a living animal with a history of engagement and 
learning. This is odd, because Gibson's overall project throughout the book is to deny that perception is a separate phenomenon in this way, and to promote the view the perception and action are inherently one and the same process.

We suggest, then, that Gibson was right to point out the 'troublesome' ambiguity of the term 'environment', and that he was prescient in noting that this ambiguity 'may cause confusion'. Indeed, it has caused confusion. The tension can be resolved, but not in the manner that Gibson proposed. Instead, we need to make a further distinction, between: the environment as it exists for a typical member of a species, a habitat; and the environment as it exists for a particular living animal, an umwelt.

We will not belabor this distinction in the text by attempting to provide watertight definitions of the three concepts of world, habitat, and umwelt. Instead we offer a set of illustrative differences in Table 1 . We will discuss most of these differences in the remaining discussion.

Table 1: some distinctions between world, habitat, and umwelt

\begin{tabular}{|c|c|c|}
\hline PHYSICAL WORLD & HABITAT & UMWELT \\
\hline Structure & Resource / function & Meaning \\
\hline Scale-free; atoms to galaxies & Terrestrial scale & Terrestrial scale \\
\hline View from nowhere & $\begin{array}{l}\text { Ideal perspective for typical } \\
\text { member of a species }\end{array}$ & $\begin{array}{l}\text { Has a first-person } \\
\text { perspective }\end{array}$ \\
\hline $\begin{array}{l}\text { Exists prior to any animal } \\
\text { encountering it }\end{array}$ & $\begin{array}{l}\text { Exists for typical member of a } \\
\text { species }\end{array}$ & $\begin{array}{l}\text { Brought forth through } \\
\text { development and active } \\
\text { exploration; enacted }\end{array}$ \\
\hline No complementary term & Complementary to 'species' & Complementary to 'organism' \\
\hline \multirow[t]{4}{*}{ Correspondence relations } & Affordance-resources & $\begin{array}{l}\text { Opportunities and } \\
\text { solicitations }\end{array}$ \\
\hline & Landscape of affordances & Field of affordances \\
\hline & Potential opportunities & Opportunities \\
\hline & $\begin{array}{l}\text { Affordances as dispositional } \\
\text { properties of the habitat }\end{array}$ & $\begin{array}{l}\text { Affordances as relations in } \\
\text { the umwelt }\end{array}$ \\
\hline $\begin{array}{l}\text { Thermodynamic information; } \\
\text { Shannon information }\end{array}$ & Information-about the habitat & $\begin{array}{l}\text { Information-for an exploring } \\
\text { organism }\end{array}$ \\
\hline
\end{tabular}




\begin{tabular}{|l|l|l|}
\hline & $\begin{array}{l}\text { Conventional information (in } \\
\text { the human habitat) }\end{array}$ & $\begin{array}{l}\text { Saturated with linguistic } \\
\text { behavior (in humans) }\end{array}$ \\
\hline History of pure structure & Has a history in evolution & Has a history in development \\
\hline Reconfigured by processes & $\begin{array}{l}\text { Expanded by animal activities } \\
\text { (niche construction) }\end{array}$ & Enriched by skill acquisition \\
\hline & Target of learning & Location of learning \\
\hline Orthogonal to social & Differentiated in learning & Enriched by learning \\
\hline processes & $\begin{array}{l}\text { Shared among members of a } \\
\text { species; continues to exist } \\
\text { when a given animal dies }\end{array}$ & $\begin{array}{l}\text { Ceases to exist when a } \\
\text { particular animal dies }\end{array}$ \\
\hline Points in space & Behavior settings & Places \\
\hline Orthogonal to life & $\begin{array}{l}\text { Complementary to a form of } \\
\text { life }\end{array}$ & $\begin{array}{l}\text { Complementary to a living } \\
\text { creature }\end{array}$ \\
\hline
\end{tabular}

\section{Some tensions and their resolutions}

Dividing the environment concept in two, as we propose here, requires quite a change in how we think about the rest of Gibson's book, and indeed about the forty years of research that has followed. The entire program is predicated on treating 'the environment' as an unproblematic fundamental: we are ecological psychologists and we study animal-environment systems. That we are currently speaking about a typical member of a species residing in the environment (of that species), or that we are talking about a particular animal in its environment (its umwelt) - we have treated this as a detail.

Over the years, though, contradictions and controversies have built up. The fact that we are still wrestling with what are supposedly the core concepts of the field so many years after the program was instituted suggests that the basic distinctions that Gibson made may not have been quite fine enough.

We here focus on four key areas where the contradictions bite most acutely. We suggest that the habitat-umwelt distinction can help resolve the tensions that have arisen in each of these cases. We focus on affordances, information, learning, and the social.

\subsection{Nobody knows what affordances are anymore}


Firstly, a tension has arisen in the literature over how we should think of affordances: are they dispositional properties, relational properties, or something else?

Gibson does not get to down to defining affordances until chapter 8 of the book. The way he initially defines affordances there is dependent on the distinction made in chapter 1. 'The affordances of the environment,' he writes, 'are what it offers the animal...' (Gibson 1979/2015, p. 119). Notice that 'the environment' is here treated as an unproblematic term. Indeed, the way Gibson begins chapter 8 seems to imply that affordances are properties of the habitat, in our terms: they are objective features to be found 'out there'. They are a special way of describing the layout of surfaces and objects, perhaps. They are to be understood independently of any given animal, and are therefore not properties of the umwelt. Thus, Gibson asks, 'How do we get from surfaces to affordances? And if there is information in light for the perception of surfaces, is there information for the perception of what they afford?'

Consistent with this way of describing affordances as things that are 'out there', Turvey (1992) attempted to formalize affordances as dispositional properties belonging to objects, surfaces, and the like. On this account, affordances are actualized when they come into contact with an animal that possesses a complementary dispositional property, namely an effectivity. A flight of stairs has a property, 'climbable', that is actualized when a stair-climbing animal comes along and climbs the stairs.

In a similar vein, Reed (1996, p. 26) insists that affordances 'are aspects of the environment of all organisms, not just features of the environment of one creature.' Reed proposes that affordances are in fact resources, or persisting features of the habitat of a species. Because of this, affordances are able to exert evolutionary selection pressure on populations across generations.

So that is one story about affordances: they are 'out there' properties that animals can encounter. The problem is that Gibson also suggested an entirely different way of thinking about affordances. A couple of pages into chapter 8 , he writes, 'an affordance is neither an objective property nor a subjective property; or it is both if you like. ... It is equally a fact of the environment and a fact of behavior' (Gibson 1979/2015, p. 121). Again, summarizing the chapter, Gibson writes, 'Affordances are properties taken with reference to the observer. They are neither physical nor phenomenal' (Gibson 1979/2015, p. 135).

This rather complicates matters. Now it seems as if Gibson is insisting that affordances are, after all, properties of the umwelt of a given organism, in addition to being simply 'out there' as properties of the habitat. 
Attempting to demystify this neither-subjective-nor-objective quality of affordances, Chemero (2003) proposed that affordances should be treated not as simple 'out there' properties of the habitat, but as relational properties that arise, or can potentially arise, in the encounter of an animal and its surroundings (see also Stoffregen, 2003). An advantage of this way of thinking is that it allows us to talk about differences between individual members of a species. The plane affords flying to the pilot but not to the child because the affordance is defined relative to the individual's skills or abilities (Chemero, 2009).

Other theorists have expanded on this affordances-as-relations concept. Withagen et al. (2012) argued that affordances do not merely exist as bare possibilities for action, but can sometimes invite or solicit particular behaviors, as when a furniture store is arranged so as to guide customers through it along a particular path. Erik Rietveld and his colleagues propose that we should think of our surroundings as a 'landscape of affordances', that is, as a whole set of possibilities that constitute our ecological niche (Rietveld and Kiverstein, 2014). This is to be distinguished from the 'field of affordances' or the finite set of possibilities that are available to us at a given moment, those that stand out as relevant to us (Bruineberg and Rietveld, 2014; van Dijk and Rietveld, 2017).

It remains an outstanding question whether a single formalization of the affordance concept can capture everything that Gibson intended it to explain (Michaels, 2003). For present purposes, we suggest that at least some of the disagreement in the field can be resolved by pointing out that affordances serve a different purpose depending on whether we are invoking them as properties of the habitat or as properties of the umwelt. In the former case, they are dispositional properties or resources, they exist independently of any given animal, and they exert selection pressure. In the latter case, they are relational properties, they depend for their existence on the continued existence of a particular living animal, and they change as that animal develops new abilities and skills (and conversely they disappear as the animal 'forgets' those skills or as its abilities degenerate with age or injury).

We can have all of the features of affordances-as-resources without rejecting the features of affordances-as-relations, and vice versa. These two accounts of affordances are not in fact in conflict with one another. One is proper to the habitat, the other is proper to the umwelt.

\subsection{Nobody knows what information is anymore}

A second outstanding tension has arisen in the context of attempts to understand Gibson's ecological conception of information. Gibsonians have traditionally understood information as structure in energy arrays that serves a dual role: it is 
both about the structure in the world that caused the pattern in the array, and it is for an active organism, i.e. it serves to guide action in a concrete sense (Michaels and Carello, 1981, p. 37).

This dual conception of information originates in the attempt by Gibson's followers to formalize Gibson's approach into a workable scientific program. Turvey et al. (1981) proposed that information should be understood as the central term in a 1:1:1 relation standing between structure in the world and structure in perception. An important claim is that this relation can be read in both directions. Structure in the world specifies how energy (light, sound waves, etc.) is structured, and this in turn specifies what an animal perceives. Thus there is information in the energy that is about the structure in the world. In the other direction, an animal is understood as an active explorer of its surroundings: it needs to seek out places and resources that are favorable for its ongoing existence. It needs to explore such that what it perceives specifies appropriate structure in light that specifies appropriate structure in the world. It has to seek information for its own purposes. This two-way specifying relation is known as the symmetry principle.

A worry here is that this way of describing perception might be simply too rigid. Meaning is understood as a purely external phenomenon, as being located entirely 'out there'. This seems to leave the animal with a limited role: to be a living animal is simply to respond to structure that one comes across. Indeed, this property of the ecological approach has proved to be offputting even to some working in neighboring non-representational approaches to cognition, who one might think would be sympathetic. For instance, Varela et al. (1991) dismiss Gibson's approach on the grounds that Gibson's conception of information relies on an unresolved dualism: because meaning is understood to be external, they suggest, there remains an explanatory gap between structure in the world and the biological and phenomenological processes that allow a living animal to make use of that structure. Gibsonians, these authors assert, are attempting to build a "theory of perception entirely from the side of the environment" (Varela et al., 1991, p. 204). The suggestion is that a theory that contains both information-about and information-for is a theory that maintains a mind-body dualism.

One strategy for answering this critique has been to concede that informationabout is a problematic concept, because it implies meaningful content 'out there' that somehow has to be integrated into the living perception-action processes of an exploring animal. Van Dijk et al. (2015) argue that all we need is informationfor: "Information for" calls attention to the fact that ecological information need not be about anything - has no "aboutness" - prior to use, but it is for something to an active animal. It is for perceiving the environment, for acting on affordances and the likes.' We do not endorse this strategy. 
Another strategy is to abandon the symmetry principle and allow that information can carry structure that is about more than simply physical surfaces and their layout. Several authors have proposed that the concept of information should be expanded so that it can account for things that we perceive but that do not specify structure in the world in the rigid, lawful ways demanded by the symmetry principle (Withagen, 2004; Withagen and Chemero, 2009; Chemero, 2009; Golonka, 2015; Bruineberg et al., 2018). According to these proposals, some information is conventional information. This allows, for example, that the label on a can of beer is informative about the can's contents because the can exists within an ongoing system of social practices. This notion of conventional information means that information is in part dependent on our activities as a community of convention-makers and -observers. This seems like a necessary move if one wishes to develop an ecological approach to deal with cultural and language-involving phenomena. To capture the nature of linguistic phenomena, however, we will need an account of how we create and use linguistic structures, in addition to an account of how we recognize that objects such as beer labels have meanings about things beyond what they are made of. We will recommend below that the appropriate move is to treat language as a social phenomenon, i.e. as an interpersonal process not reducible to a perceptual process.

For now we note that another possibility exists which may allow us to maintain all three concepts discussed here: information-about, information-for, and the symmetry principle (for non-conventional information). The solution is to understand information-about as a property of the habitat, while information-for should be understood as a property of the umwelt. There is indeed structure in energy arrays that can potentially be used to guide activity. A fruit pie cooling on a windowsill emits a chemical trail into the air that can be detected by an animal with the appropriate olfactory system. There is information about the pie that can be said to exist in the habitat of animals of that type. The chemical composition of the pie is specified in the chemicals diffused in the air, as required by the symmetry principle and unlike in the case of the beer label. When a particular animal does detect the chemical trail and starts to navigate up the scent gradient towards the pie, we should understand the animal as using information for its own

pie-seeking purposes. It is both proper to say that the pie is specified in patterns in the energy array, and that information is actively sought by a living animal.

\subsection{How do animals learn? How do we invent?}

A third tension arises from a lack of clarity over the status of learning in Gibson's account. This tension can be traced directly to the decision made by James J.

Gibson and his wife Eleanor J. Gibson in the 1960s to divide their research efforts: the former would focus on the senses while the latter would focus on perceptual learning (Gibson, 1966, p. viii). This division, made between the Gibsons for their 
own convenience, has had a long-lasting consequence: the developmental part of the ecological account has ever since remained somewhat separate from the 'core' perception-action program (Rader, 2018).

To understand the tension here it is useful to turn to a foundational paper in perceptual learning. Gibson and Gibson (1955) argue that the traditional way of framing the learning process is incorrect. The traditional view has it that learning about the world is building up and maintaining an internal store of knowledge about external facts: learning is a process of enrichment. The Gibsons propose that a more useful way of thinking about learning is to acknowledge that what the animal comes into contact with - the stimulus - is already richly structured, and the task that the learner is faced with is to seek out distinguishing features in the stimulus that allow the learner to recognize things in the world as being different from one another: learning is a process of differentiation. The go-to examples here are how wine experts come to recognize differences in taste between different wines, and how workers tasked with categorizing the sex of newly hatched chicks come to recognize male from female. In both instances, the learning process seems to be highly implicit: skilled perceivers in these tasks may not necessarily be able to articulate precisely what it is that allows them to carry out their categorizations. Yet they are discriminating, and they must be doing so by having learned to attend to some variable, or set of variables, in the perceptual stimulus.

The problem here is that while that what these expert perceivers are doing is discriminating perceptual structure, not enriching an internal model, this does not actually constitute an account of the learning process. Indeed, in a sense it is misleading, because from a phenomenological standpoint it remains true that learning results in a richer experience of the world. The pilot who has learned how to fly the plane has a richer set of behavioral possibilities open to her, she has a richer umwelt, even if this is arrived at in part through learning to perceptually discriminate between the levers and buttons on the flight control panel. We should even acknowledge here that this enrichment is possible because of changes in the organization of the pilot's body and nervous system, though of course this does not imply that the pilot has built a second, mental version of the control panel inside her head that she is using to control the plane. There is just more in the pilot's umwelt.

In recent years, several authors have developed a theory of 'direct learning' which attempts to formalize the discrimination viewpoint and turn it into a workable empirical program (Jacobs and Michaels, 2007; Jacobs et al., 2009). The innovation here is the suggestion that the optimum variable that an actor should be attending to, in learning to carry out some task, is already specified in the information space of possible solutions to the task. To become an expert in some task the actor has to explore this information space and seek a trajectory towards 
some optimum solution. This is a powerful view of learning, but it is a view that is still dependent on there being pre-existing structure 'out there' that the animal is able to explore. It is hard to see how this same approach might be applied to the kind of generative behaviors that children routinely engage in, namely those involving language or pretend play. Children do not merely explore a space of pregiven solutions, but invent and create.

The developmental story remains an underdeveloped part of the ecological approach. For now we note only that the Gibsons' dichotomy between differentiation and enrichment accounts of perceptual learning is not fine enough. Again it is useful to think of the differences between the habitat and the umwelt. In the habitat, a space of possible actions and discriminations exists before any particular organism comes into existence, and this information space may well serve as the target of learning. In the umwelt, meanwhile, the world comes to have shape in part because of changes in the animal: learning does indeed result in an enrichment of possibilities from the perspective of the living animal.

\subsection{Can we have a Gibsonian account of the social?}

The fourth issue we wish to discuss here is the problem of reconciling Gibson's approach with an account of social phenomena. Owing largely to the work of Harry Heft, effort in this area has been focused on taking Gibson's theory of perception as a starting point and trying to unite it with the 'other' ecological psychology, that of Roger Barker and his colleagues (Barker, 1968; Heft, 2001; McGann, 2014).

Barker's project was one of attempting to classify and understand the behaviors that a typical person engages in in their daily life. He and his team of researchers investigated this by observing people's actual behavior in non-laboratory settings, namely, in a small town in Kansas over a number of years. The central insight of this project is that a person's behavior is best predicted at a given instant not by what other events have just occurred, as is implied in the methodology of the stimulus-response psychology that was dominant at the time. Behavior is instead best predicted by the places where those behaviors occur. A given child's behavior in a classroom or a candy store will closely resemble that of her peers when her peers are in the same behavior setting. To know how the child will likely behave, it is more useful to know where she is right now than it is to know what kinds of behaviors she has engaged in earlier in the day.

The tension here is this. Perceiving a behavior setting, say a reading group, as a specific instance of that behavior settings seems to require that we as individual actors and observers in some sense stand outside that setting, that we categorize it as an instance of 'reading group' before we are able to enter into it and participate. 
But this cannot be correct. Reading groups do not exist simply as things that are furnished by the natural world. Rather, they exist because we enact them. How can it be that such settings are at once things that we encounter and things that we create?

In a recent paper, Heft (2018) briefly acknowledges this tension: 'a behavior setting is an emergent property of interdependent patterns of action over time among individuals and "milieu," using Barker's terminology. From this vantage point, it can be seen that a particular child does not enter into the behavior setting, as an individual might enter an enclosure, but rather that the child joins a behavior setting as a participant and in doing so contributes to its ongoing functioning.'

This description still does not quite resolve the tension, however. To join a behavior setting is still to enter into something that is already ongoing. This still leaves mysterious how it is that new behavior settings ever emerge, as they must.

Here it is again helpful to invoke the habitat-umwelt distinction. The resolution lies in allowing that there is indeed structure in the habitat: behavior settings exist as discoverable, observable units of collective behavior. There are post offices and train stations and French classes. But in the umwelt we do not need to perceive that we are in a given behavior setting. Rather, the behavior settings that exist around us are what we grow into. The umwelt of a given individual is shaped by the places where that individual dwells, and by the history of interactions that the individual participates in.

Costall (1995) argued that the social does not have to be so much incorporated into the ecological approach as demystified. This argument remains a valuable one. In the umwelt of a child, everything is already social. In fact, the social comes first. The structure of the child's surroundings is, prenatally, entirely constituted by and mediated through its mother's body. Following birth the child's surroundings are shaped by the ongoing social practices of caregivers and community. Only through many years of education and learning can the child come to master its settings and take control of its interactions in a manner we are inclined to label 'adult'.

In the case of language, we are both confronted with a pre-existing set of linguistic conventions and resources (a community of speakers of a language), and we are enactors of that language. A child language learner must learn to control its own linguistic behavior with reference to the activities it engages in, progressing from babbling to vocalizing words to skillfully using novel syntactic structures as a means of directing the attention of self and other. It is reasonable to say that certain aspects of a natural language are properties of the habitat: dictionaries, grammars, social judgments of particular dialects and ways of talking, etc. We should not, however, jump to the conclusion that an individual's 'personal' language is simply a property of her umwelt. Language is not simply 'out there', 
from the perspective of an individual speaker. It is not simply something we perceive, but also a form of acting (Baggs, 2015). As adults, our language is so thoroughly integrated into our self-regulation processes and thinking that it must be something other than simply a set of 'external' resources. Take counting. When, as children, we learn to count, we start by reproducing an auditory sequence that is modeled by more skilled speakers around us, "one, two, three, four...". We reproduce this sequence in interaction with other people. Later, this same sequence can serve to structure our own activities: tracking sets of objects, time-telling, measuring, etc. What began as a social phenomenon has entered into the process of self-regulated activity. In early childhood this behavior is enacted 'out loud'. As the child becomes more skilled she learns to count 'in her head'. Language has to be 'internalized', in the sense that what starts off as an entirely public behavior in the child comes, over time, to be integrated into her selfregulation processes, in turn enabling new behaviors that were not previously available (Vygotsky, 1978). The problem of explaining how the social comes to enter into individual self-regulation processes is the problem of explaining the qualitative shift that separates the human form of life from that of the other species.

\section{The Ecological Approach as a theory of the structure of the habitat}

All of this leads us to a point where we must re-evaluate exactly what project Gibson is engaging in in The Ecological Approach to Visual Perception. Of course, in a basic sense he is simply writing a book about visual perception. But in another sense he is attempting something much more than that. According to Reed (1988, p. 2), Gibson concentrated for so many years on direct perception because he believed 'that a breakthrough in the understanding of perceptual awareness and knowledge would carry in its wake a new approach to the whole of psychology.' Gibson's followers have pursued this broader aim: the ecological approach as a new approach to psychology itself. Indeed, when Gibsonians eventually set up their own journal, they called it Ecological Psychology, the suggestion being, perhaps, that the approach had already matured into a fully elaborated scientific research program.

Gibson himself, though, never used the term 'ecological psychology', at least not as far as we are aware, although he did contribute to a collection put together by his followers whose subtitle was 'Towards an Ecological Psychology' (Shaw and Bransford, 1977). It remains unclear in what sense it is appropriate to talk of an 'ecological psychology' at all. In the opening sentence of his Principles of Psychology, William James provides the following definition: 'Psychology is the Science of Mental Life, both of its phenomena and of their conditions' (James, 
1890). Following this definition, Gibson's Ecological Approach can perhaps be read as an unprecedented account of the conditions of mental life: it is an account of the structure of things 'out there' - the structure that an animal can potentially come into contact with. What it is generally not is an account of what animals actually $d o$ when they come into contact with their surroundings.

Another way of phrasing this is to say that Gibson gives an account of the structure of the habitat. Surfaces, layout, and points of observation in an ambient optic array: these are all idealized descriptions of the structures available to a potential animal. Indeed, it is arguably the case that what Gibsonians have been doing ever since is describing the structure of behavior in the habitat. Take the well-studied example of braking to avoid a collision (Fajen, 2005). The aim of this research program has been to uncover optimal control laws or strategies that a person can use in controlling their braking. In other words, the aim is to characterize the information space of a task. Warren (2006) notes that this strategy imposes a limit on the level of predictive explanatory power that we can hope to achieve: 'researchers may need to be satisfied with theories that capture the dynamical "deep structure" of behavior - the morphology of attractors, repellers, and bifurcations for a given task - rather than one that can precisely predict individual behavior on particular occasions.' Another way to understand this description of the methodology in terms of 'deep structure' is to appreciate that control laws reside in the habitat. What is not included is an account of what occurs whenever a particular living thing actually encounters some piece of worldly structure and attempts to act with reference to it (though see Fajen, 2008, for a discussion of learning in the specific case of braking to avoid collision).

In recent years, a number of authors have been attempting to combine Gibson's insights with those of the enactivist approach instituted by Maturana and Varela (Maturana and Varela, 1980; Varela et al., 1991); the aim here is to establish a full-blown post-cognitivist science of the mind (Chemero, 2009; McGann, 2014; van Dijk et al., 2015; Hutto and Myin, 2017; Di Paolo et al., 2017). The central insight of the enactivist approach is that mind is a living process (Thompson, 2007). That is, mental activity is self-producing, in the sense that the organism produces and maintains a boundary between itself and the world; it is asymmetrical in the sense that the organism does something to its surroundings across the boundary that it has itself established; and it is normative in the sense that the animal acts in accordance with norms that are established, for example, by the biological need to act in an adaptive manner (Di Paolo et al., 2017).

The combined ecological-enactive program has yet to fully take off. It is possible that long-standing confusion over the scope of the ecological approach has been an obstacle here. It may be important to recognize that the bulk of research in the ecological approach has been targeted at the habitat, that is, at describing structure 
as it exists for an ideal member of a species. The enactive approach, by contrast, aims to provide a theory of the animal-in-its-umwelt. Properly understood, there is no reason why these two approaches cannot inform and support one another.

Can we still be realists, if we are to talk about individual animals in their umwelts? Gibsonians have always considered themselves to be realists, in the sense that perception-action is said to be targeted directly at structure 'out there' in the world, not mediated via some mental copy of that structure. Enactivists, by contrast, typically align themselves with constructivism, which is an explicitly anti-realist position according to which living organisms bring forth their surroundings from a subjective point of observation (Riegler, 2005).

We believe it is possible to resolve even this contradiction. The solution will be to pursue a dialectical version of realism (see also Di Paolo et al., 2017, chapter 6). Structure exists at the habitat level, and this structure exists independently of any single living organism. For a living organism, meanwhile, the world is viewed from a particular perspective. In the course of our activities we gradually uncover more of reality by a process of learning and interaction, and at the same time, through our activities, we alter the structure of the habitat for ourselves and those around us. The umwelt is not an inner copy of the habitat, but it is the habitat considered from the point of view of the ongoing activity of a particular living organism.

\section{Practical ecological interventions}

The success of a behavioral science research program should ultimately be measured by what it can be used for. The distinction we are proposing provides a useful way of categorizing the kinds of things we might be able to do with such a science. The habitat/umwelt distinction implies two ways in which the ecological approach can inform practical interventions in everyday life. First, we can reconfigure the habitat in order to make it easier for actors to carry out some task. Secondly, we can reconfigure the animal by educating them to attend to their surroundings, their umwelt, in a particular way, while leaving the habitat unchanged.

We focus on a single example here: interventions designed to encourage safer road crossing. Existing work within the ecological approach has attempted to address this problem in the umwelt. Lee et al. (1984) describe a training system for teaching children to safely cross existing roads. Lee and his colleagues set up a 'pretend road' on the sidewalk alongside an actual road, and asked children to cross it 'as if crossing the adjacent road in the face of oncoming vehicles'. The authors argue that this is a useful training regime, and they conclude that 'children should be trained in crossing in the presence of traffic at an early age.' Here is a 
curious point. The empirical program in the ecological approach has largely targeted the habitat, as described above. When Gibsonians have attempted to apply their insights outside the laboratory, however, they have tended to treat the habitat as unchanging, and have instead targeted the umwelt as the locus of intervention. Lee et al. (1984) treat roads as if they were a natural feature of reality to which children must be trained to adapt.

An underexplored type of intervention is in the habitat. Marshall (2018) asks a useful question here: why are roads so much safer in Australia than they are in the United States, as measured by fatality statistics (the fatality rate in the US is more than twice as high)? The discrepancy appears to be down to differences in the structure of the habitat. Partly, it is argued, there is stricter enforcement of regulations in Australia. But the roads are also physically designed in a different way in the two countries. In Australia there are a great deal many more roundabouts at places where in the US there would be a light-controlled four-way intersection. Roundabouts are inherently safer because they do not give rise to opportunities for the most severe types of inter-vehicle collisions: head-on and Tbone crashes (Rodegerdts et al., 2010). The roads in Australia are also generally less wide, meaning that pedestrians have less width to cross, and drivers are more cautious in their speed because a narrower travel corridor makes greater demands on drivers in terms of accurately controlling their position in the road.

The tools of the ecological approach are well suited to capturing why certain features of road infrastructure are more successful, i.e. safer, than others. More effort should be devoted to exploring interventions in habitats outside the laboratory using these tools.

\section{Concluding remarks}

In this chapter we have argued that Gibson's distinction between the physical world and the animal environment should be refined. The latter term should be subdivided. We should appreciate the difference between the species-specific habitat and the animal-specific umwelt.

Making clear this distinction allows us to resolve several long-standing tensions in the field. The notions of affordance and information can be better understood if we allow that habitat resources are different from active relational engagements, and that arrays of energy are different from self-regulating organisms actively seeking out structured patterns. These notions are not in conflict with one another, but are complementary.

Similarly, the phenomena of learning and social interaction can be better understood by keeping distinct the setting of behavior and the process through 
which that behavior comes to take shape over time as an individual becomes a skillful participant in a social practice.

One last question: does this mean that we have to stop talking about 'animalenvironment systems'? If the term 'environment' is ambiguous, then should we abandon it in favor of more accurate terms - 'species-habitat' and 'animalumwelt' systems? This does not strike us as an attractive conclusion. We like the phrase 'animal-environment system'. We are used to it. It is part of the family. For the purposes of this chapter, we have avoided talking about 'the environment'. But perhaps the term need not be problematic as long as its meaning is appropriately constrained by context.

\section{Acknowledgements}

Edward Baggs was supported by funding from the European Union's Horizon 2020 research and innovation programme under grant agreement No 706432. Anthony Chemero was supported by the Charles Phelps Taft Research Center.

\section{References}

Baggs, E. (2015). A Radical Empiricist Theory of Speaking: Linguistic Meaning Without Conventions. Ecological Psychology, 27(3):251-264.

Barker, R. G. (1968). Ecological Psychology. Stanford University Press, Stanford, California.

Bruineberg, J., Chemero, A., and Rietveld, E. (2018). General ecological information supports engagement with affordances for 'higher' cognition. Synthese, pages 1-21.

Bruineberg, J. and Rietveld, E. (2014). Self-organization, free energy minimization, and optimal grip on a field of affordances. Frontiers in Human Neuroscience, 8:599.

Chemero, A. (2003). An outline of a theory of affordances. Ecological Psychology, 15(2):181-195.

Chemero, A. (2009). Radical Embodied Cognitive Science. MIT Press, 
Cambridge, Massachusetts.

Costall, A. (1995). Socializing affordances. Theory \& Psychology, 5(4):467-481.

Di Paolo, E., Buhrmann, T., and Barandiaran, X. (2017). Sensorimotor Life: An Enactive Proposal. Oxford University Press, Oxford.

Fajen, B. R. (2005). Calibration, information, and control strategies for braking to avoid a collision. Journal of Experimental Psychology: Human Perception and Performance, 31(3):480-501.

Fajen, B. R. (2008). Perceptual learning and the visual control of braking. Perception \& Psychophysics, 70(6):1117-1129.

Gibson, J. J. (1966). The Senses Considered as Perceptual Systems. HoughtonMifflin, Boston.

Gibson, J. J. (1967). New reasons for realism. Synthese, 17(1):162-172.

Gibson, J.J. (2015). The Ecological Approach to Visual Perception. Psychology Press, New York, NY. (Original work published 1979)

Gibson, J. J. and Gibson, E. J. (1955). Perceptual learning: Differentiation or enrichment? Psychological Review, 62(1):32.

Golonka, S. (2015). Laws and conventions in language-related behaviors. Ecological Psychology, 27(3):236-250.

Heft, H. (2001). Ecological Psychology in Context: James Gibson, Roger Barker, and the legacy of William James's radical empiricism. Lawrence Erlbaum Associates, Mahwah, NJ.

Heft, H. (2018). Places: Widening the scope of an ecological approach to perception-action with an emphasis on child development. Ecological Psychology, 30(1):99-123.

Hutto, D. D. and Myin, E. (2017). Evolving Enactivism: Basic minds meet content. MIT Press, Cambridge, Massachusetts.

Jacobs, D. M. and Michaels, C. F. (2007). Direct learning. Ecological psychology, 19(4):321-349.

Jacobs, D. M., Silva, P. L., and Calvo, J. (2009). An empirical illustration and formalization of the theory of direct learning: The muscle-based perception of kinetic properties. Ecological Psychology, 21(3):245-289. 
James, W. (1890). The Principles of Psychology. Henry Holt and Company, New York.

Lee, D. N., Young, D. S., and McLaughlin, C. M. (1984). A roadside simulation of road crossing for children. Ergonomics, 27(12):1271-1281.

Marshall, W. E. (2018). Understanding international road safety disparities: Why is Australia so much safer than the United States? Accident Analysis \& Prevention, 111:251-265.

Maturana, H. R. and Varela, F. J. (1980). Autopoiesis and Cognition: The realization of the living. D. Reidel, London.

McGann, M. (2014). Enacting a social ecology: radically embodied intersubjectivity. Frontiers in Psychology, 5:1321.

Michaels, C. F. (2003). Affordances: Four points of debate. Ecological Psychology, 15(2):135-148.

Michaels, C. F. and Carello, C. (1981). Direct Perception. Prentice-Hall, Englewood Cliffs, NJ.

Rader, N. d. V. (2018). Uniting Jimmy and Jackie: Foundation for a research program in developmental ecological psychology. Ecological Psychology.

Reed, E. S. (1988). James J. Gibson and the Psychology of Perception. Yale University Press, New Haven, Connecticut.

Reed, E. S. (1996). The Necessity of Experience. Yale University Press, New Haven, Connecticut.

Riegler, A. (2005). The constructivist challenge. Constructivist Foundations, $1(1): 1-8$.

Rietveld, E. and Kiverstein, J. (2014). A rich landscape of affordances. Ecological Psychology, 26(4):325-352.

Rodegerdts, L., Bansen, J., Tiesler, C., Knudsen, J., Myers, E., Johnson, M., Moule, M., Persaud, B., Lyon, C., Hall- mark, S., Isebrands, H., Crown, R. B., Guichet, B., and O'Brien, A. (2010). Roundabouts: An informational guide. Transportation Research Board, Washington, DC, 2nd edition.

Shaw, R. and Bransford, J., editors (1977). Perceiving, Acting, and Knowing: Towards an Ecological Psychology. Lawrence Erlbaum Associates, Hillsdale, New Jersey. 
Stoffregen, T. A. (2003). Affordances as properties of the animal-environment system. Ecological Psychology, 15(2):115- 134.

Thompson, E. (2007). Mind in Life: Biology, Phenomenology, and the Sciences of Mind. Harvard University Press, Cambridge, Massachusetts.

Turvey, M. T. (1992). Affordances and prospective control: An outline of the ontology. Ecological psychology, 4(3):173-187.

Turvey, M. T., Shaw, R. E., Reed, E. S., and Mace, W. M. (1981). Ecological laws of perceiving and acting: In reply to Fodor and Pylyshyn (1981). Cognition, 9(3):237-304.

Van Dijk, L. and Rietveld, E. (2017). Foregrounding sociomaterial practice in our understanding of affordances: The skilled intentionality framework. Frontiers in psychology, 7:1969.

Van Dijk, L., Withagen, R., and Bongers, R. M. (2015). Information without content: A Gibsonian reply to enactivists' worries. Cognition, 134:210-214.

Varela, F. J., Thompson, E., and Rosch, E. (1991). The embodied mind: Cognitive science and human experience. MIT Press, Cambridge, Massachusetts.

Vygotsky, L. S. (1978). Mind in Society: The development of higher psychological processes. Harvard University Press, Cambridge, Massachusetts.

Warren, W. H. (2006). The dynamics of perception and action. Psychological Review, 113(2):358-389.

Withagen, R. (2004). The pickup of nonspecifying variables does not entail indirect perception. Ecological Psychology, 16(3):237-253.

Withagen, R. and Chemero, A. (2009). Naturalizing perception: Developing the Gibsonian approach to perception along evolutionary lines. Theory \& Psychology, 19(3):363-389.

Withagen, R., de Poel, H. J., Arau 'jo, D., and Pepping, G. (2012). Affordances can invite behavior: Reconsidering the relationship between affordances and agency. New Ideas in Psychology, 30(2):250-258. 